questions and answers including any answers that have been revised in the light of guidance. The print-out does not, however, set out the ethical and legal principles which have been portrayed on screen and may have influenced the user in revising his answer. This is a disadvantage if the 'case' is subsequently being used for group discussion.

I found the guidance and the conclusions to be very much in line with current thought although I was disappointed that I was told that it would be unethical for me to give any treatment purely for research purposes even to an adult who had been fully informed of the circumstances, was competent in every way and had freely given his consent. But this would be a case in which as the program states there may be a difference of view, and would be a basis for group discussion.

Technically the program is very easy to use and no knowledge of computing or even of typing is necessary. The User's Guide is clear, though it would have been helpful to have had a line on how to make a print-out rather than to be told to refer to the computer manual which is, as they all are, notoriously complex. With the disk comes free a copy of the BMA Handbook of Medical Ethics, the GMC's booklet on Professional Conduct and Discipline and the book Doctors' Dilemmas by Phillips and Dawson.

What then are the uses of this program? Not, I suggest, to give a young doctor an immediate answer to his ethical problem when faced with an emergency. Rather will it be useful to the student, undergraduate or postgraduate studying alone or as part of a group. The program will provoke thought and discussion. I enjoyed using it and, to the student and recent graduate who is accustomed to being stimulated and taught by computer rather than by books, it will be invaluable. The authors are to be congratulated on this innovation and we look forward to further programs in the series.

ARCHIE DUNCAN, Vice-President, Institute of Medical Ethics, Professor (Emeritus) of Medical Education, University of Edinburgh 1 Walker Street EH3 $7 \mathcal{F Y}$

\section{Critical Issues in the Early Development of Premature Infants}

Sibylle K Escalona, 284 pages, New

Haven and London, £31.50, Yale

University Press, 1987

In recent years advances in both understanding and technology have improved the survival rates for low birth weight (LBW) infants and attempts are now made to save babies previously considered non-viable. Along with these advances concern has been expressed that the number of surviving but handicapped infants may be increasing and there is growing interest in the quality of life of the survivors.

Centres all over the world are now reporting results achieved with modern intensive neonatal care and these data are providing evidence for considering whether and where limits should be set in supporting the lives of tiny, sick newborns.

Sibylle Escalona, a developmental psychologist, conducted a longtitudinal study of 106 infants and their families who were part of one such large multidisciplinary research project, looking at the outcome of LBW survivors. The conduct and results of her study are the subject of this book. Each child and family was studied intensively until the child was aged 40 months. This has enabled detailed comparisons to be made of developmental achievement within each of the groups of intact survivors, those with neurological problems, and those with behavioural problems. Much of her study concentrated on factors which influenced the abilities of the survivors without handicap.

As would be expected socioeconomic background was shown to have a marked effect on the outcome. Analysing this further Dr Escalona found that the development of the ability to control behaviour, so as to delay seeking immediate gratification of desires was learnt from the parents, and occured earlier in the families from higher socio-economic backgrounds. Furthermore the IQ of these infants correlated with the age of development of this impulse control. Whether this correlation will outlast the pre-school period is not answered in this study.

The research findings are fleshed out by vignettes of some of the children and families in each of the groups.

Much of this book is only of specialist interest. Developmental psychologists interested in factors which vary with social background could use these findings to form the basis for further research enquiry. The more general reader will probably find this a book to dip into or to skim, rather than to read $\frac{\AA}{m}$ comprehensively. The ethical aspects of $\underset{\vec{\sim}}{\stackrel{m}{*}}$

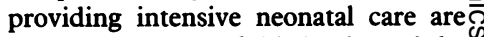
outside the scope of this book, and the "absence of an index is a shortcoming.

RICHARD WEST,

Senior Lecturer in Child Health, $\frac{\bar{\sigma}}{\bar{N}}$ Department of Child Health, $\frac{\Phi}{7}$ St George's Hospital Medical School, London SWI7)

\section{Growing Old in the Future}

Steering Committee on Future Health Scenarios, edited by C F Hollander and H A Becker, 305 pages, Dordrecht, Netherlands, £34.50, Martinus

Nijhoff, 1985

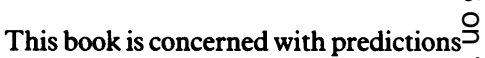
of future 'scenarios' for the health and social circumstances of the elderly in the Netherlands, by a committee of experts $\widetilde{\Phi}$ in medicine, public health, and the social sciences. It contains few figures $\mathbb{D}$ and consists of detailed, mainly verbal, discussion of the likely patterns off factors influencing the health afo health care of the elderly to the year 2000.

The so-called 'reference scenario' based on an extrapolation of currento trends, and this serves as a basis for theô three other scenarios. These describe@ respectively the prospects in the event $\vec{F}$ of increased demand for health care, $\frac{0}{3}$ decreased demand for health care, and $\bar{\neg}$ finally in the case of two conceivable developments. The first is a five-yearincrease of the age at onset of dementia, $\overline{3}$ the second is a breakdown of intergenerational solidarity so that children no longer care for theit: parents.

This book is interesting both for its careful analysis of the serviceo implications of issues important? throughout the developed world and foro its clear illustration of the difficulties of prediction in complex social issues. $\mathrm{N}$ Moderately different extrapolations of existing trends can lead to very different으 futures even over such a short period asc the time remaining to the end of the century, and of course no trend can bee relied on to remain constant. However $\frac{}{x}$ the 'scenarios' remain useful, if only as as basis from which to extrapolate the effects of unexpected technical or socialo developments.

The book includes no consideration of issues in medical ethics: for example,, euthanasia is discussed only in terms of its effects on health services. The book 